\title{
Surface Modification of TFC-PA RO Membrane by Grafting Hydrophilic pH Switchable Poly(Acrylic Acid) Brushes
}

\author{
Muhammad Asad Abbas, ${ }^{1}$ Shehla Mushtaq, ${ }^{1}$ Waqas A. Cheema, ${ }^{1}$ Hazim Qiblawey, ${ }^{2}$ \\ Shenmin Zhu, ${ }^{3}$ Yao Li, ${ }^{3}$ Runnan Zhang, ${ }^{4,5}$ Hong Wu, ${ }^{4,5}$ Zhongyi Jiang, ${ }^{4,5}$ Rehan Sadiq, \\ and Nasir M. Ahmad $\left.{ }^{1}\right)^{1}$ \\ ${ }^{1}$ Polymer Research Lab, School of Chemical and Materials Engineering (SCME), National University of Sciences and \\ Technology (NUST), H-12 Sector, Islamabad 44000, Pakistan \\ ${ }^{2}$ Department of Chemical Engineering, College of Engineering, Qatar University, P.O. Box 2713, Doha, Qatar \\ ${ }^{3}$ State Key Laboratory of Metal Matrix Composites, Shanghai Jiao Tong University, Shanghai 200240, China \\ ${ }^{4}$ Key Laboratory for Green Chemical Technology of Ministry of Education, School of Chemical Engineering and Technology, \\ Tianjin University, Tianjin 300072, China \\ ${ }^{5}$ Collaborative Innovation Center of Chemical Science and Engineering, Tianjin 300072, China \\ ${ }^{6}$ School of Engineering, Faculty of Applied Science, Okanagan Campus, EME4242-1137 Alumni Ave., Kelowna, BC, Canada V1V 1 V7
}

Correspondence should be addressed to Nasir M. Ahmad; nasir.ahmad@scme.nust.edu.pk

Received 4 January 2020; Accepted 6 April 2020; Published 22 May 2020

Academic Editor: Sagar Roy

Copyright @ 2020 Muhammad Asad Abbas et al. This is an open access article distributed under the Creative Commons Attribution License, which permits unrestricted use, distribution, and reproduction in any medium, provided the original work is properly cited.

\begin{abstract}
The grafting of pH-responsive poly(acrylic acid) (PAA) brushes was carried out on the surface of a commercial TFC-PA membrane using surface-initiated atom transfer radical polymerization (SI-ATRP). Poly(t-butyl acrylate) was polymerized through the SIATRP method followed by its acid hydrolysis to form PAA hydrophilic polymer brushes. Surface morphology, permeation flux, salt rejection, and pore sizes were investigated. The contact angle for water was reduced from $50^{\circ}$ for a pristine membrane to $27^{\circ}$ for the modified membrane due to a modification with the hydrophilic functional group and its brush on membrane surfaces. The flux rate also increased noticeably at lower $\mathrm{pH}$ values relative to higher $\mathrm{pH}$ for the modified membranes, while the flux remains stable in the case of pristine TFC-PA membranes. There is slight transition in the water flux rate that was also observed when going from $\mathrm{pH}$ values of 3 to 5 . This was attributed to the $\mathrm{pH}$-responsive conformational changes for the grafted PAA brushes. At these $\mathrm{pH}$ values, ionization of the $\mathrm{COOH}$ group takes place below and above $\mathrm{p} K_{a}$ to influence the effective pore dimension of the modified membranes. At a lower $\mathrm{pH}$ value, the PAA brushes seem to permit tight structure conformation resulting in larger pore sizes and hence more flux. On the other hand, at higher $\mathrm{pH}$ values, PAA brushes appeared to be in extended conformation to induce smaller pore sizes and result in less flux. Further, $\mathrm{pH}$ values were observed to not significantly affect the $\mathrm{NaCl}$ salt rejection with values observed in between $98.8 \%$ and $95 \%$ and close to that of the pristine TFC-PA membranes. These experimental results are significant and have immediate implication for advances in polymer technology to design and modify the "switchable membrane surfaces" with controllable charge distribution and surface wettability, as well as regulation of water flux and salt.
\end{abstract}

\section{Introduction}

The commercially available reverse osmosis membrane (RO) technologies are widely used to produce clean and safe drinkable water [1]. One of the major concerns for the RO membrane technology is to control its flux rate and salt rejection. In addition, it would be of significant interest to develop a membrane based on polymer technology with simultaneous switchable flux and salt rejection as water compositions vary considerably [2]. In this direction, membrane surface morphology such as surface roughness, charge, and pore size can affect the performance of the membranes [3]. 
The switching in the wetting character of the membrane is due to the charge on the membrane surface that affects the permeability of the membrane $[4,5]$. For example, surface morphology and wettability are known to control the adsorption behaviour of molecules including protein [6]. Thus, the tunability of the membrane flux rate as well as salt rejection still remains a significant challenge and considerable efforts are underway both academically and industrially [7]. Various physical and chemical techniques have been proposed to modify the membrane surface to switch the flux rate and salt rejection to enhance membrane performance [8]. For this purpose, the control of the membrane structure is needed, which may not always be feasible. Several factors such as the nature of the polymer, solvents and concentration, temperature, and composition of the coagulation bath govern the performance and the structure of the prepared membrane [9]. Another way to switch the membrane performance is to functionalize the membrane surface which can be achieved by coating, self-assembly, plasma treatment, and chemical grafting [10]. These techniques are being applied to varying extents to advance the process and system of water treatment through membrane development. For example, thin-film composite polyamide (TFC-PA) membranes are widely used because of their superior performance in terms of their wide operating $\mathrm{pH}$ range, water flux, and good resistance in microbiological species attack [11]. In most of the recent work, the polymeric polyamide (PA) layer of the RO membrane was modified without much switchable characteristics. Typical examples include surface coating by sulfonated polyvinyl alcohol (SPVA), modification with MWCNTs, and grafting of poly(sulfobetaine methacrylate) [12]. Among the different methods employed are chemical methods including photoinduced grafting [13], gamma ray [14], electron beaminduced grafting [15], plasma treatment and plasma-induced grafting [16], thermal-induced grafting, immobilization [17], and surface-initiated polymerizations [18]. These methods have their distinct advantages; however, surface-initiated atom transfer radical polymerization (SI-ATRP) has recently emerged as one of the most versatile techniques to functionalize the surface of the RO membranes through grafting of polymer brushes [18]. Moreover, SI-ATRP enables carrying out the polymerization at mild conditions and a variety of vinyl monomers have been polymerized in a controlled way and well-defined structures can be achieved to develop tailored membranes with optimized performance [19]. For example, grafting of switchable polymer brushes provides potential for tailoring membrane surfaces with tunable properties in response to various stimuli such as $\mathrm{pH}$, temperature, and light [20]. In this context, $\mathrm{pH}$-responsive polymer brushes are widely investigated to develop membranes with regulation of flux and salt rejection [21]. In one of the interesting studies, different types of grafted membranes were prepared based on poly(acrylic acid), poly(methacrylic acid), poly(ethacrylic acid), polypeptide, and poly-(L-glutamic acid) [22]. Changes in water permeation were reported at various $\mathrm{pH}$ values of 3.0, 4.0, and 6.8. Furthermore, conformation transformation in the helix coil was observed with expansion at high $\mathrm{pH}$ to reduce pore diameter in porous membranes [23]. Dual responsive membranes with $\mathrm{pH}$ and temperature response were also prepared through SI-ATRP of block copolymers of poly(NIPAAm-block-DMAEM) [24]. The reversible change in water permeation was observed at pHs between 6 and 8 and at temperatures between 30 and $35^{\circ} \mathrm{C}$ [25].

The above-mentioned and other relevant studies indicate the novel potential of the $\mathrm{pH}$ switchable functional polymer membrane technology for water treatment [26]. One of the main research challenges that remain is to develop $\mathrm{pH}$ switchable functional membrane technology with optimized performance in terms of relatively higher flux as well as salt rejection for RO membranes [27]. It is in this context that the current work envisages to functionalize the surface of commercially available membranes of TFC-PA with the simple $\mathrm{pH}$-sensitive carboxyl group - $\mathrm{COOH}$ of poly(acrylic acid) (PAA). The growth of pH-responsive PAA brushes by SIATRP was achieved through various steps such as the functionalization of TFC-PA membranes by APTMS and followed by bromination through the attachment of the initiator molecules, polymerization of poly(t-butyl acrylate) $\mathrm{P}(\mathrm{t}-$ BA) at radical sites, and finally hydrolysis. The contact angle for surface wettability, optical profilometry for surface roughness and SEM for surface morphology, and FTIR for functional group analysis were performed at each step of modification. Water flux at various $\mathrm{pH}$ and salt rejection studies were carried out for both the pristine and modified membranes. The characteristics of the $\mathrm{pH}$-responsive $-\mathrm{COOH}$ groups of the functionalized polymer brush membranes are studied due to $\mathrm{pH}$-responsive protonation/deprotonation and subsequent volume shrinkage/expansion of the polymer chains as well as their conformation [28]. This effect correlates to the regulation of the aqueous solution permeability and solute rejection through a variation in the pore sizes of the membrane as a function of $\mathrm{pH}$ value [29]. These experimental results are significant and have immediate implication for advances in polymer technology to design and modify the "switchable membrane surfaces" with controllable charge distribution and surface wettability, as well as regulation of water flux and salt.

\section{Material and Methods}

2.1. Materials. All the chemicals and reagents were acquired from Sigma-Aldrich of analytical grade. The chemicals used were 3-aminopropyl trimethoxysilane (97\%), $\alpha$-bromoisobutyl bromide (98\%), triethylamine (99.5\%), copper (I) bromide (CuBr, 98\%), PMDETA $\left(\mathrm{N}, \mathrm{N}, \mathrm{N}^{\prime}, \mathrm{N}^{\prime \prime}, \mathrm{N}^{\prime \prime}\right.$-pentamethyl diethylene triamine) (99\%), t-butyl acrylate (t-BA, 98\%), tetrahydrofuran (99.9\%), glacial acetic acid, dichloromethane, and trifluoroacetic acid. Nitrogen gas of analytical grade was obtained from Linde Pakistan Limited.

\subsection{Method}

2.2.1. Membrane Functionalization. For the functionalization of the PA membrane, a TFC-RO membrane was cut into four pieces, each having a dimension of 2 in sq. $60 \mathrm{ml}$ of distilled water was poured into a $100 \mathrm{ml}$ culture bottle, and 4-5 drops of APTMS were added into the bottle. The pieces of 
membrane were dipped into the solution, and the bottle was sealed and left for an hour. After an hour, the membrane pieces were removed and dried in a vacuum oven at room temperature for 5 hours. The molar ratios of the initiator, monomer, and ligand were kept at 0.033:0.34:0.0034, respectively. Typically, a solution of $0.37 \mathrm{ml} \alpha$-bromo isobutyl bromide and $0.41 \mathrm{ml}$ TEA was mixed in $60 \mathrm{ml}$ of dry DCM. It was injected over the APTMS substrate in the presence of $\mathrm{N}_{2}$ at room temperature over membranes in a round-bottom flask with continuous stirring for 1 hour. After an hour, the membranes were removed and washed with DCM and ethanol. Afterwards, the membranes were dried in the vacuum oven at $60^{\circ} \mathrm{C}$ for $1 \mathrm{hr}$ to obtain the initiator functionalized samples. $60 \mathrm{mg}$ of PMDETA, $5 \mathrm{ml}$ of t-butyl acrylate (acting as a monomer), and $90 \mathrm{mg}$ of $\mathrm{CuBr}$ were added in a $10 \mathrm{ml}$ glass vial containing membranes. The vial was placed in a preheated water bath at $60^{\circ} \mathrm{C}$ and then stirred for $4 \mathrm{hrs}$ at $300 \mathrm{rpm}$ on a hot plate. The prepared membranes were washed with THF and dried in a vacuum oven at $40^{\circ} \mathrm{C}$ for $4 \mathrm{hrs}$. After grafting of $\mathrm{P}(\mathrm{t}-\mathrm{BA})$ on the TFC-RO membrane, it was then subjected to hydrolysis. $40 \mathrm{ml}$ of DCM was poured into a bottle, and $1.5 \mathrm{ml}$ TFA was added to it. Then, these membranes were placed in the bottle for 10 mins. The membranes were washed with DCM and dried in a vacuum oven at $40^{\circ} \mathrm{C}$ for $4 \mathrm{hrs}$. After each step, the membranes were analyzed with the help of FTIR, optical profilometry, contact angle analysis, and optical microscopy.

2.2.2. Characterization of Membrane. Various characterization techniques and methods were employed to characterize the pristine and modified membrane. The chemical structure of all the modified membrane samples was investigated through an FTIR-ATR Bruker ALPHA spectrophotometer. All the samples had a size of 1 in sq. and were dried thoroughly under vacuum at $40^{\circ} \mathrm{C}$ at best for $4 \mathrm{hrs}$ before analysis. The contact angle was measured by a custom-made apparatus. The method employed for measurement was a static sessile drop. A $10 \mu \mathrm{l}$ drop of distilled water was released onto the membrane surface. Images were taken with a camera and further processed with ImageJ software. For the removal of experimental errors, at least five different measurements were recorded, and an average was calculated. Scanning electron microscopy (SEM) (JEOL JSM 6490A) was used to investigate the morphology, cross-section, and topography of modified membranes. The membranes were cut into $1 \mathrm{~cm}^{2}$ pieces, stacked on a steel stud using carbon tape, gold coated, and analyzed. An optical profilometer (NANOVEA PS50) was used for the measurement of the surface roughness of membrane samples. The membrane samples were cut into $1 \mathrm{~cm}^{2}$ pieces and then placed on the platform for measurement. A permeation flux test was performed using the vacuum filtration assembly at a constant pressure of $3309.48 \mathrm{kPa}$ at room temperature. The membrane had an area of $0.00025 \mathrm{~m}^{2}$. Flux and flow measurements were measured using the following:

$$
\text { Flux }=\frac{\text { flow rate }}{\text { area }} \times \text { time, }
$$

Flow rate $=$ initial volume - final volume

To study the effect of $\mathrm{pH}$, water samples of varying $\mathrm{pH}$ values of 3-10 were produced through the addition of diluted $\mathrm{HCl}$ and $\mathrm{NaOH}$ solutions. The respective $\mathrm{pH}$ solution was later used to obtain permeation flux as discussed above. Salt rejection is an important feature to evaluate membrane performance including its capability to remove contaminants. Salt rejection was calculated using

$$
\text { Salt rejection } \%=\frac{\text { conductivity of feed water }- \text { conductivity of permeate water }}{\text { conductivity of feed }} \times 100
$$

\section{Results and Discussions}

\subsection{Functionalization of TFC-PA Membrane through ATRP.} Reactions involving the functionalization of a TFC-PA membrane by APTMS and follow-up surface reaction and modification are presented in Scheme 1. The overall scheme for the growth polymer brushes on a membrane surface is illustrated in Scheme 1(a), and reactions to modify the surface membrane are presented in Scheme 1(b). The TFC-PA membrane surface modification with an initiator molecule followed by ATRP on their initiating sites to grow $\mathrm{P}(\mathrm{t}-\mathrm{BA})$ brushes is presented.

The reaction scheme for the synthesis of polymer brushes is shown in Scheme 1(b) that shows the formation of the Si-O$\mathrm{C}$ and $\mathrm{Si}-\mathrm{O}-\mathrm{Si}$ bond between the APTMS and polyamide layer, thus forming the coating [30]. The amine group on the APTMS served as the reactive center. $\alpha$-Bromo isobutyl bromide reacted with this amine group as shown in Scheme 1(b) B. Thus, a bromine atom was exposed which served as an active species for ATRP $[31,32]$. Scheme 1(b) $\mathrm{C}$ shows that the bromine functionalized polyamide membrane was subjected to ATRP and resulted in the controlled polymerization of t-butyl acrylate onto the polyamide membrane in the form of $\mathrm{P}(\mathrm{t}-\mathrm{BA})$ brushes [33]. Scheme 1(b) D represents the t-butyl group hydrolyzation to a carboxylic acid group, thus converting $\mathrm{P}(\mathrm{t}-\mathrm{BA})$ to $\mathrm{PAA}$ poly(acrylic acid) [34].

3.2. FTIR Membrane Functional Group Studies. In Figure 1 for $\mathrm{PA}-\mathrm{NH}_{2}$, the peak at $3383.17 \mathrm{~cm}^{-1}$ can be attributed to $\mathrm{N}-\mathrm{H}$ bond stretching due to the presence of an amine group. 


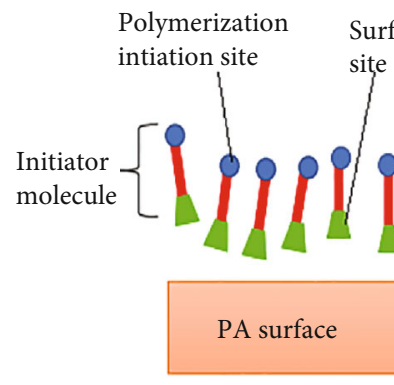

Initiator attachmen

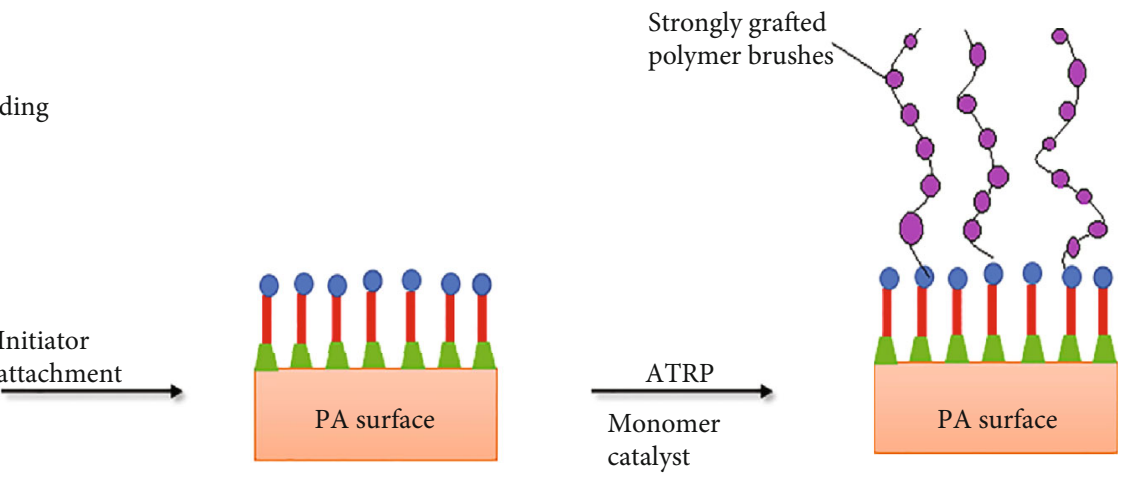

(a)

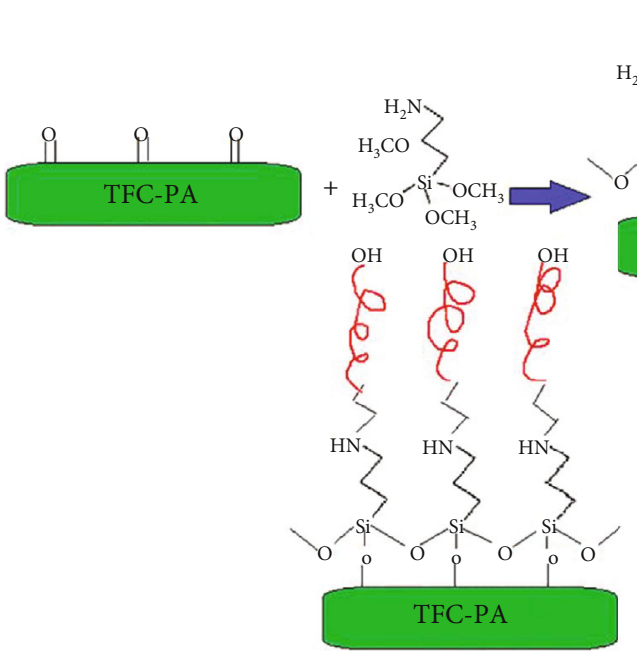

(D)

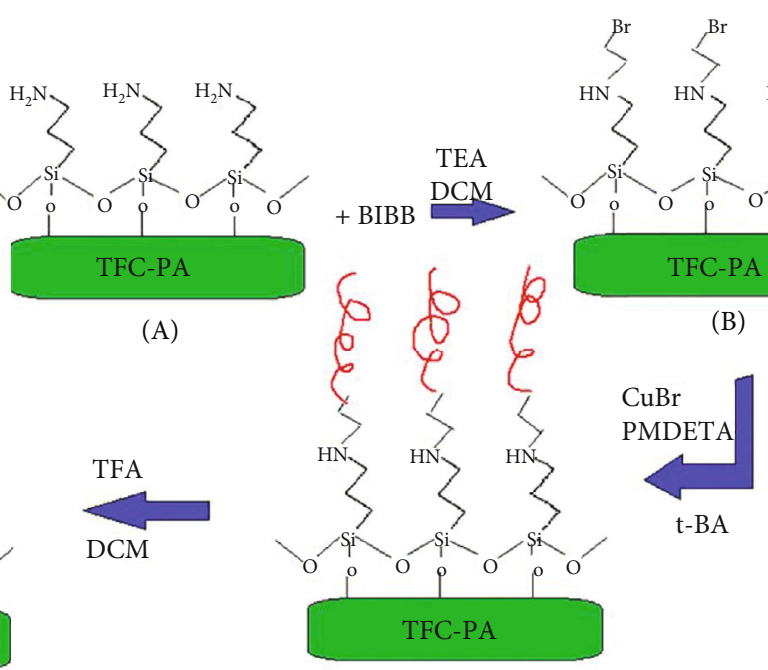

(C)

(b)

Scheme 1: Growth of polymer brushes on the membrane surface (a). Representation of the surface modification of the membrane (b), with reactions showing (A) functionalization of TFC-PA by APTMS, (B) initiator attachment over APTMS-functionalized TFC-PA, (C) growth of $\mathrm{P}(\mathrm{t}-\mathrm{BA})$, and $(\mathrm{D})$ hydrolysis of PA-g-P(t-BA) to PA-g-PAA.

The broad peak resulted from the weak N-H bond stretching. The peak at $1635.83 \mathrm{~cm}^{-1}$ is due to the $\mathrm{N}-\mathrm{H}$ bond bending. The sharp peak represents that an extensive bending had occurred in the bond. The spectra for PA-Br show that the peak which was formed due to N-H stretching and bending had disappeared. This can be attributed to the conversion of PA- $\mathrm{NH}_{2}$ to PA-Br. For PA-g-P(t-BA), the peak at 1782.6 is associated with the $\mathrm{C}==\mathrm{O}$ group. The peaks from 2977.72 to $2825.4 \mathrm{~cm}^{-1}$ represent the weak alkyl C-H stretching [35]. The peaks at 1473.54 and 1384.9 correspond to asymmetric and symmetric $\mathrm{C}\left(\mathrm{CH}_{3}\right)$ stretching, respectively $[36,37]$. The broad peak at $3323.65 \mathrm{~cm}^{-1}$ in Figure 1(b) shows the attachment of the hydroxyl group.

3.3. Surface Wettability Analyses. Figure 2 represents the contact angle of water liquid on the pristine and modified membranes. The water liquid contact angles on pristine and modified membranes of TFC-PA, PA- $\mathrm{NH}_{2}, \mathrm{PA}-\mathrm{Br}, \mathrm{PA}-\mathrm{g}$ $\mathrm{P}(\mathrm{t}-\mathrm{BA})$, and PA-g-PAA were found to be $51^{\circ}, 57^{\circ}, 83^{\circ}, 96^{\circ}$, and $27^{\circ}[5,38,39]$. The minimum contact angle was observed for the TFC-PA-g-PAA membrane. This can be attributed to the presence of carboxylic acid in PAA, which means that its surface became hydrophilic after modification. The contact angle of the PA- $\mathrm{NH}_{2}$ membrane was found to be $57^{\circ}$. This was due to the amino group. An increase in contact angle was observed after grafting $\alpha$-bromo isobutyl bromide, and it is due to the presence of the $\mathrm{Br}$ group that has a hydrophobic character [40]. The maximum contact angle of $109^{\circ}$ was shown by the TFC-PA-g-P(t-BA) membrane. This was associated to the presence of methyl groups that are hydrophobic. The conversion of PA-g-P(t-BA) to PA-g-PAA seems to have significantly reduced the contact angle. The contact angles of water pristine TFC-PA and PA-g-PAA membranes were observed to be $51^{\circ}$ and $27^{\circ}$ [41]. The contact angle of the modified PA-g-PAA-grafted membrane was significantly reduced as compared to the commercially available TFC-PA membrane by almost $50 \%$. The above surface wettability observation of the PA-g-PAA-grafted membrane was carried out for deionized water at a neutral $\mathrm{pH}$ value. The behavior of variation of water $\mathrm{pH}$ is relatively complex [42]. It is possible that water $\mathrm{pH}$ value variation can exhibit transition in the contact angle values since brushes on such surface undergo a corresponding transition in response to such ionization changes. 


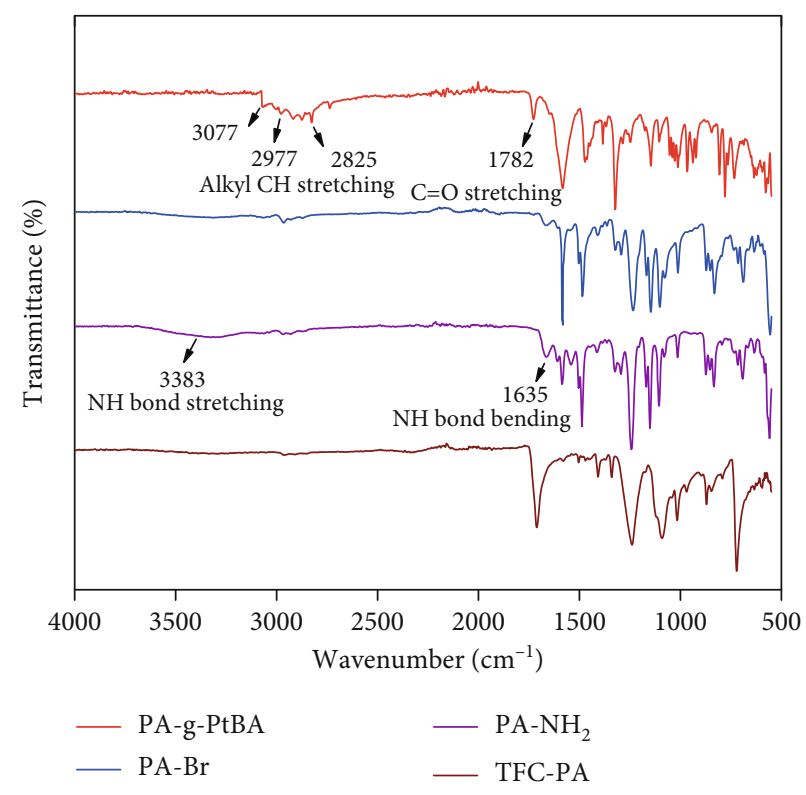

(a)

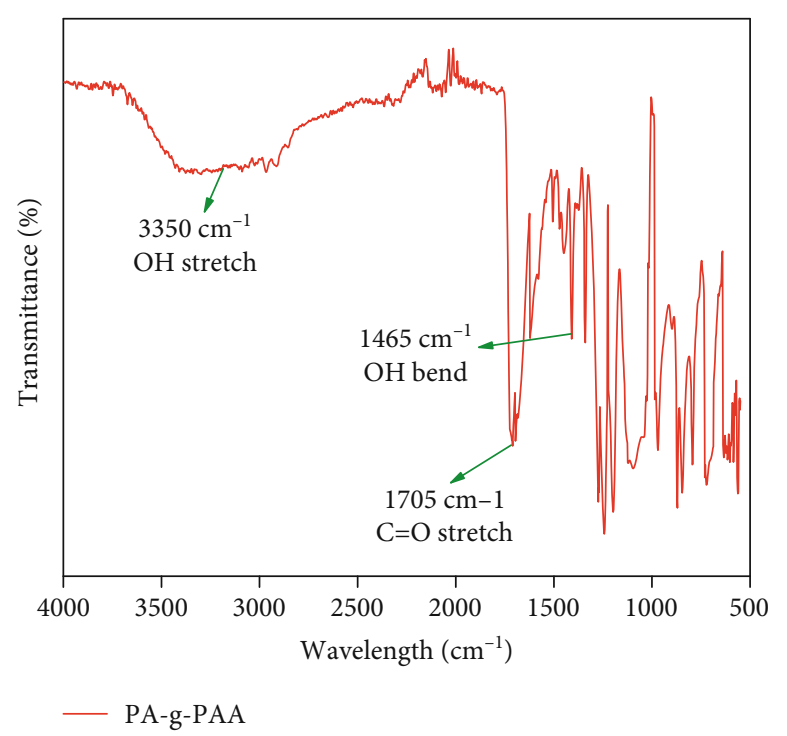

(b)

FIGURE 1: FTIR spectra of the pristine and modified membrane: (a) pristine TFC-PA membrane and its functionalization with P(t-BA) brushes; (b) functionalized P(t-BA) brushes of the membrane after hydrolysis to give PAA brushes.

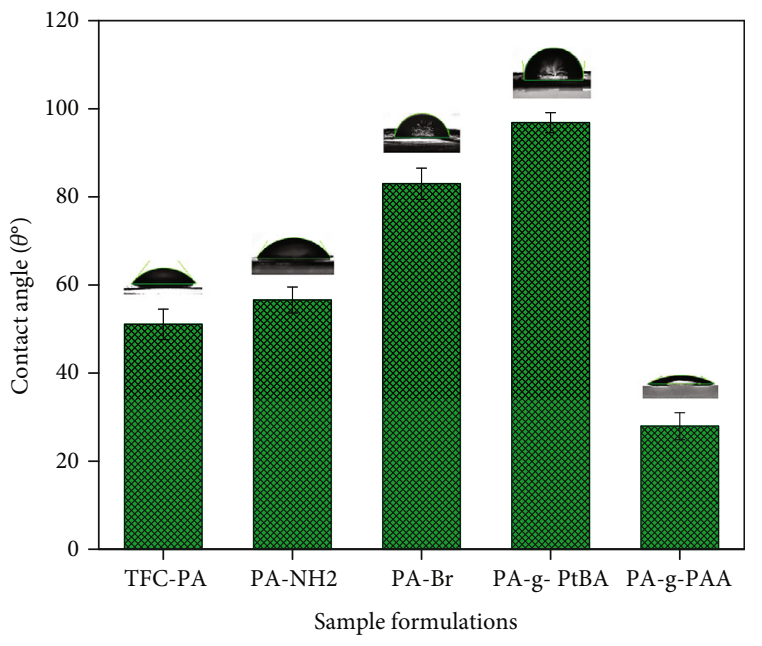

Figure 2: Contact angles of (a) TFC-PA, (b) PA-NH2, (c) PA-Br, (d) PA-g-P(t-BA), and (e) PA-g-PAA.

3.4. SEM Surface Morphology Observation. Surface topography and cross-sectional images of the pristine and modified membranes are represented in Figure 3. SEM images showed that the polymer brushes grown on the membrane had an asymmetric and finger-like structure that resulted in better flow properties. Pores ranging from $40 \mathrm{~nm}$ to $600 \mathrm{~nm}$ in size were observed. An increase in the number of large pores in the modified membranes compared to the pristine polyamide membrane was due to the growth of polymer brushes on the membrane surface. The average pore size of the pristine PA membrane was found to be $57 \mathrm{~nm}$ and that of the PA-gPAA membrane was observed to be $255 \mathrm{~nm}$. The unique rough structure of the polyamide $\mathrm{RO}$ membrane is clearly visible in Figures 3(a), 3(b), 3(e), and 3(f). This observation shows the valley and ridges, structural features made from polyamide chains during interfacial polymerization reactions [43]. These typical structural characteristics of noddle types can be originated because of interfacial polymerization involving the rapid and un-controlled nature of these reactions at the interface. The formed polyamide chains on the membrane surface are observed to be irregular in their structure [44]. Figures 3(c), 3(d), 3(g), and 3(h) represent the surface morphology and cross-section of the PA-g-P (t-BA) membrane. It was observed from the surface morphology that roughness was increased due to the grafting of $\mathrm{P}(\mathrm{t}-\mathrm{BA})$ brushes. From Figures $3(\mathrm{~g})$ and $3(\mathrm{~h})$, it is obvious that the needle-like structure represents the $\mathrm{P}(\mathrm{t}-\mathrm{BA})$ brushes. The upright growth of the $\mathrm{P}(\mathrm{t}-\mathrm{BA})$ brushes assisted the flow of the water through the membrane, and also, morphology analyses support the appropriate grafting density of the polymer brushes on the surface of the modified membranes to influence critical parameters both in the dry state, such as surface roughness, and the wet state, like that of surface wettability and water flux rates. Several studies involving polymer brushes and grafting density were investigated on $\mathrm{Si}$ surfaces through ellipsometry analyses and indicated the influence on surface roughness and surface wettability [ 45 , 46]. There are also complex studies in order to elucidate the effect of polymer chain density on fluid confinement in gradients of brushes with varying grafting densities using nanoindentation techniques [47]. The grafting of polymer brushes was also accompanied by a notable change in the membrane wettability and flux rates as indicated by the decrease in water contact angle for the modified membranes with hydrophilic brushes due to their high degree of hydration $[45,46]$. In the present work, such direct studies are not available due to the nature of the membranes; however, surface roughness, wettability, and water flux rates as observed are influenced 


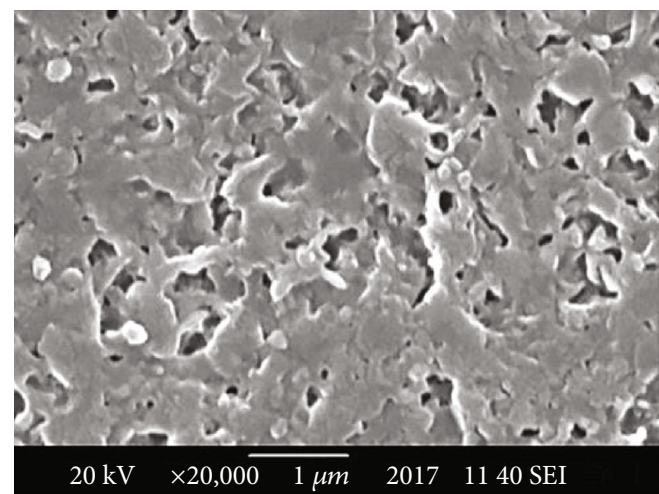

(a)

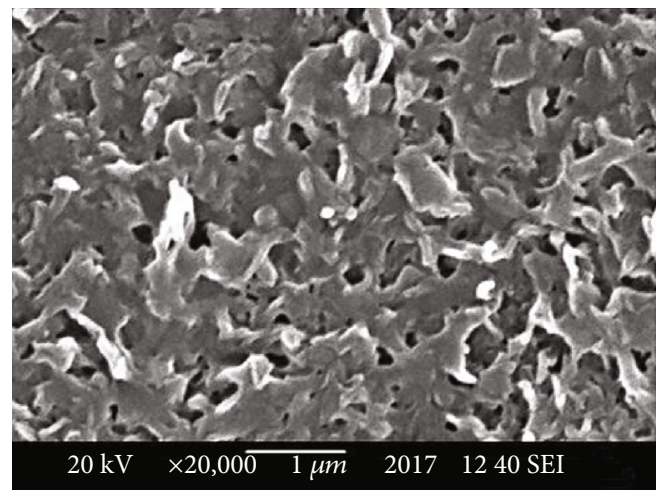

(c)

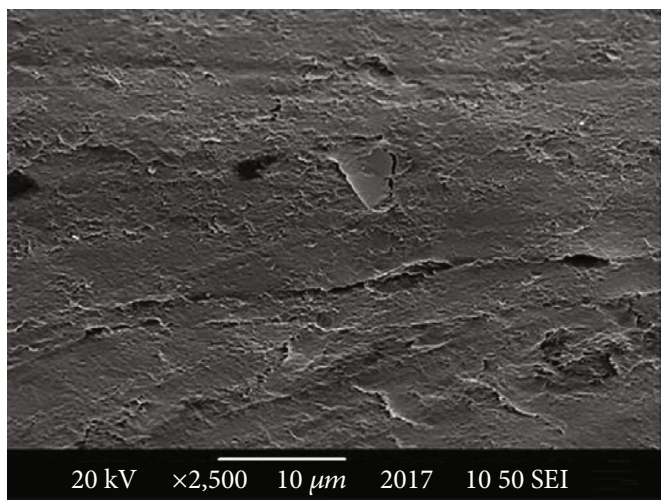

(e)

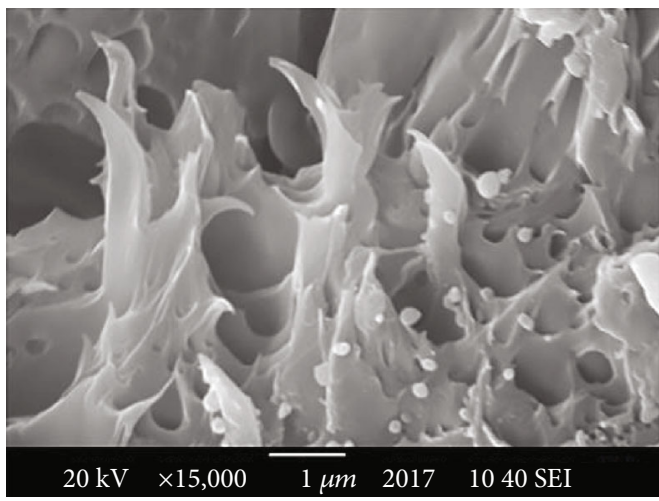

(g)

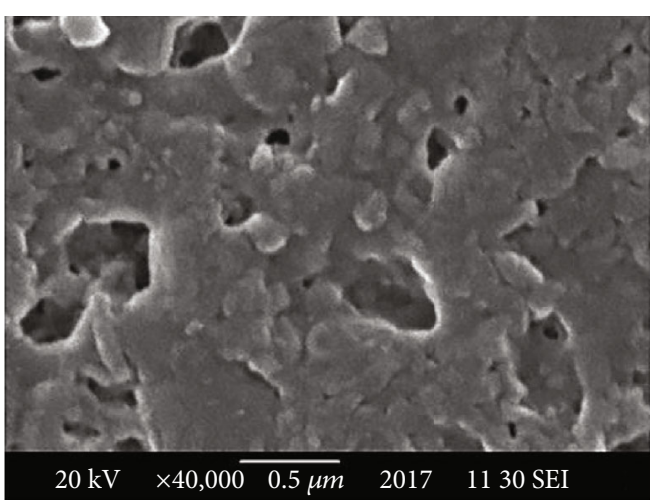

(b)

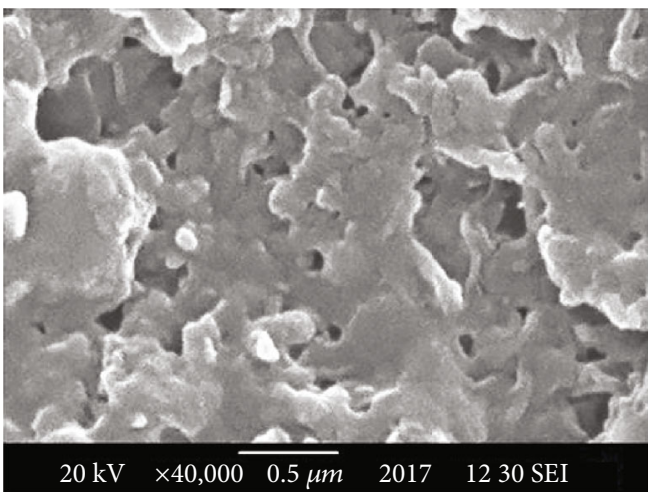

(d)

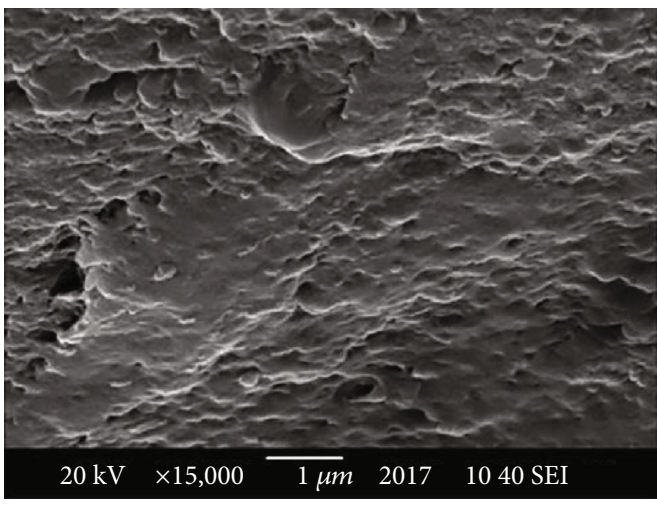

(f)

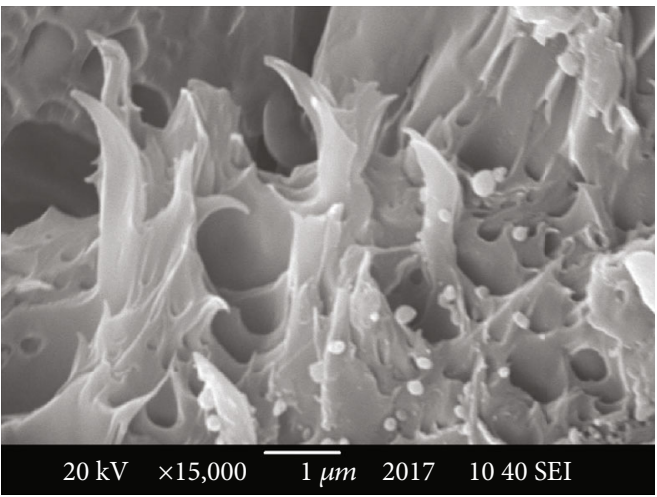

(h)

FIGURE 3: SEM images of membranes: ( $a$ and $b$ ) pristine TFC; ( $c$ and d) PA-g-PAA membrane; (e and $f$ ) cross-section of pristine membrane TFC-PA; ( $g$ and h) PA-g-PAA-grafted membrane. 


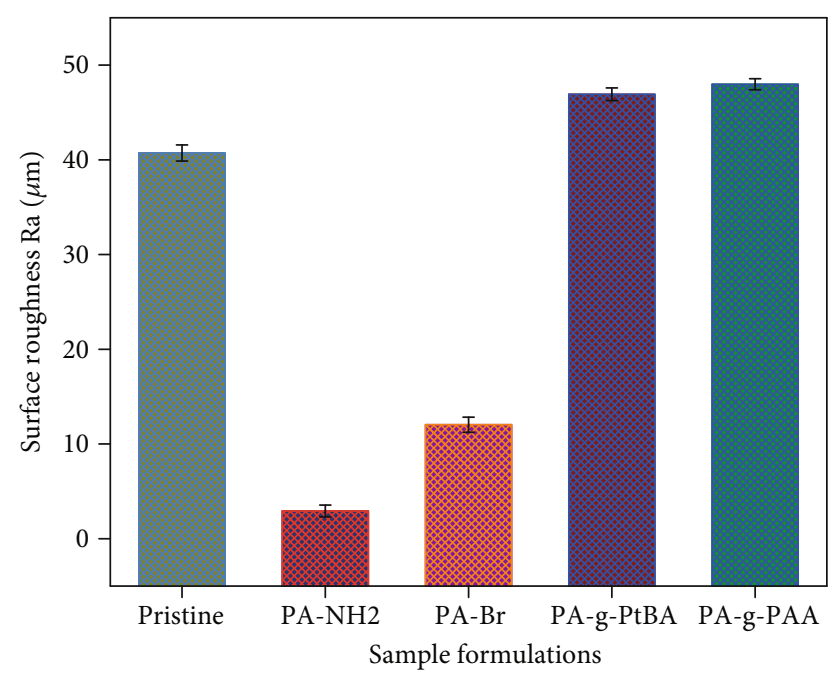

FIGURE 4: Surface roughness of the pristine TFC-PA and modified membranes.

for the modified membranes with hydrophilic brushes to support the formation of sufficient density to notably influence these parameters.

3.5. Optical Profilometry Surface Roughness Determination. Optical profilometry was used to investigate the surface roughness of the pristine and modified PA membranes. Figure 4 represents the surface roughness of the membranes. The surface roughness was increased due to the growth of polymer brushes and were found to be in good agreement with the previous work [48]. It was reported that polyamide $\mathrm{RO}$ membranes are rough due to the ridge and valley presence in their structure. The surface roughness of the PA and PA-g-P(t-BA) membranes was found to be $40 \mu \mathrm{m}$ and $46 \mu \mathrm{m}$, respectively. The increase in surface roughness of the PA-g-P(t-BA) membrane was due to the growth of polymer brushes of $\mathrm{P}(\mathrm{t}-\mathrm{BA})$ [49]. After the hydrolysis of PA-g$\mathrm{P}(\mathrm{t}-\mathrm{BA})$, this was converted to PAA. It was observed that the surface roughness was decreased after the hydrolysis. The aggregation of molecules due to the hydrogen bonding interaction may have been caused by $-\mathrm{COOH}$ moieties [38].

3.6. $p H$-Responsive Permeation Flux Evaluation. The water flux results are represented in Figure 5 as a function of $\mathrm{pH}$ value variation. At $\mathrm{pH} 2$, the highest rate of flux was observed. No significant changes in flux were observed in the pristine TFC-PA membrane at different $\mathrm{pH}$ and thus seems to be independent of it. In the case of the modified membrane of TFC-PA with grafted polymer brushes, there is a noticeable variation in flux observed as a function of acidic $\mathrm{pH}$ values. For the grafted PA-g-PAA membrane, it was observed that the maximum flux was $81 \mathrm{~L} \mathrm{~m}^{-2} \cdot \mathrm{hr}^{-1}$ at $\mathrm{pH} 3$, whereas at $\mathrm{pH} 11$, the flux rate decreased to approximately $70 \mathrm{~L} \mathrm{~m}^{-2} \cdot \mathrm{hr}^{-1}$. As illustrated in Figure 5, a slight transition in flux was noted in going from $\mathrm{pH} 3$ to $\mathrm{pH} 5$.

The variation in the flux at different $\mathrm{pH}$ was due to the protonation and deprotonation of the carboxylic group of PAA [50]. This observation can be correlated to the dissociation constant $\mathrm{p} K_{a}$ of the acrylic acid - $\mathrm{COOH}$ group of the

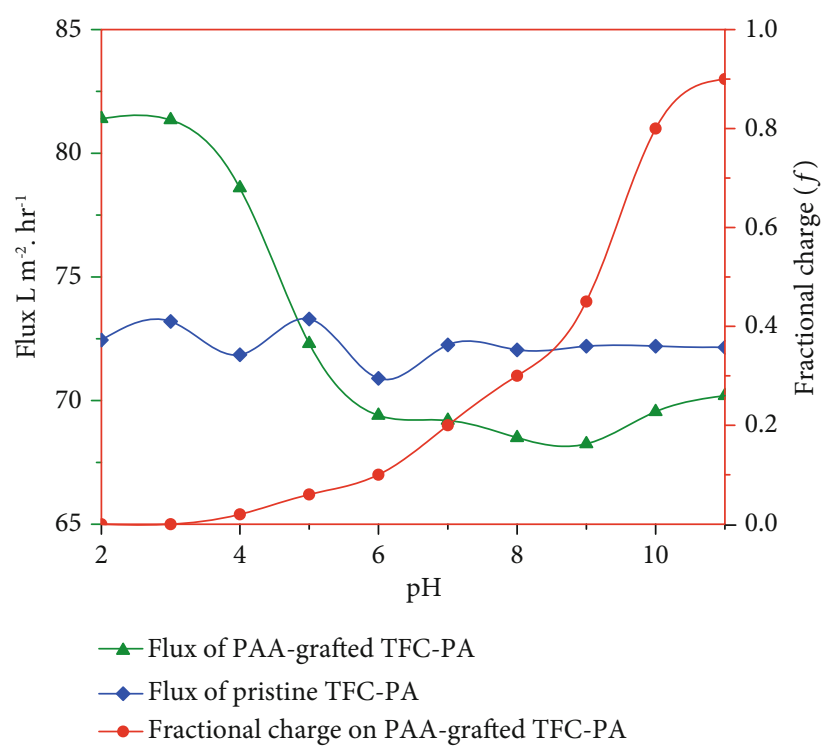

FIgURE 5: $\mathrm{pH}$ variation exhibiting flux of pristine TFC-PA and modified PA-g-PAA membranes at various $\mathrm{pH}$ and fractional charges with $\mathrm{pH}$ variation.

PAA chains. The relationship between $\mathrm{pH}$ and $\mathrm{p} K_{a}$ of PAA [51] can be discussed by Equation (4):

$$
\mathrm{pH}=\mathrm{p} K_{a}+4.10 f^{1 / 3}-\log \left\{\frac{1-f}{f}\right\},
$$

where $\mathrm{p} K_{a}$ is the dissociation constant extrapolated to $f \longrightarrow 0, f$ describes the number of charged monomers in the chain which can be used to determine the transition between helical and extended conformation. The numerical solution of the equation is estimated at various $\mathrm{pH}$ values and presented in Figure 5 .

The fractional charge governs the chain conformation which has the following effect: at low $\mathrm{pH} 3$, the chains are protonated having less fractional charge and switched into coiled confirmation which results in the increase of flux [52]. At high $\mathrm{pH} 11$, the chains are deprotonated with the increase in the fractional charge that results in the extended conformation due to the repulsion of the carboxylate ion which results in the lowering of flux [51]. Transition in flux can be explained from the consideration of the extent of fractional charges: at low $\mathrm{pH}, \mathrm{PAA}$ brush chains are not charged and adopt a coiled conformation, and at higher $\mathrm{pH}$, these PAA chains become charged and adopt an extended conformation [53]. Protonation and deprotonation of the carboxylic group (-COOH) can control the effective pore size of the PA-g-PAA brush membrane, and the effect of $\mathrm{pH}$ on the flux is shown by the proposed model in Scheme 2. Conformation changes originated due to the weak carboxylic acid group of $\mathrm{COOH}$ grafted on the chain of PAA that takes place due to ionization below and above the $\mathrm{p} K_{a}$ to influence the effective pore dimension of the modified membranes [54]. The $\mathrm{p} K_{a}$ of PAA in solution varies approximately between 4.50 and 4.55 , depending on several factors [55]. In between 


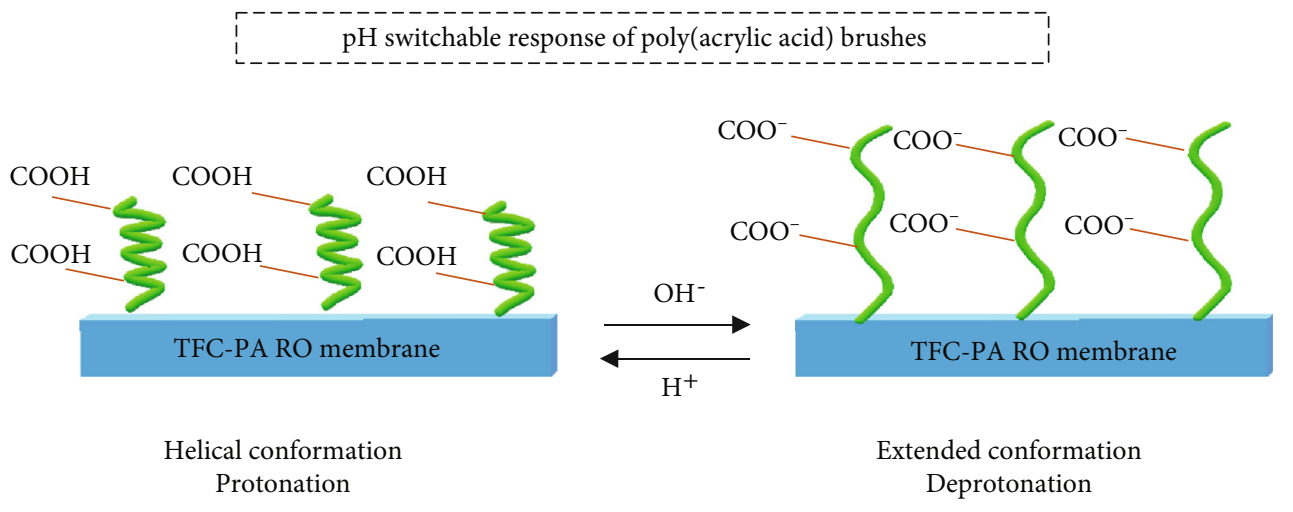

Scheme 2: Schematic presentation of protonation and deprotonation of PAA brushes.

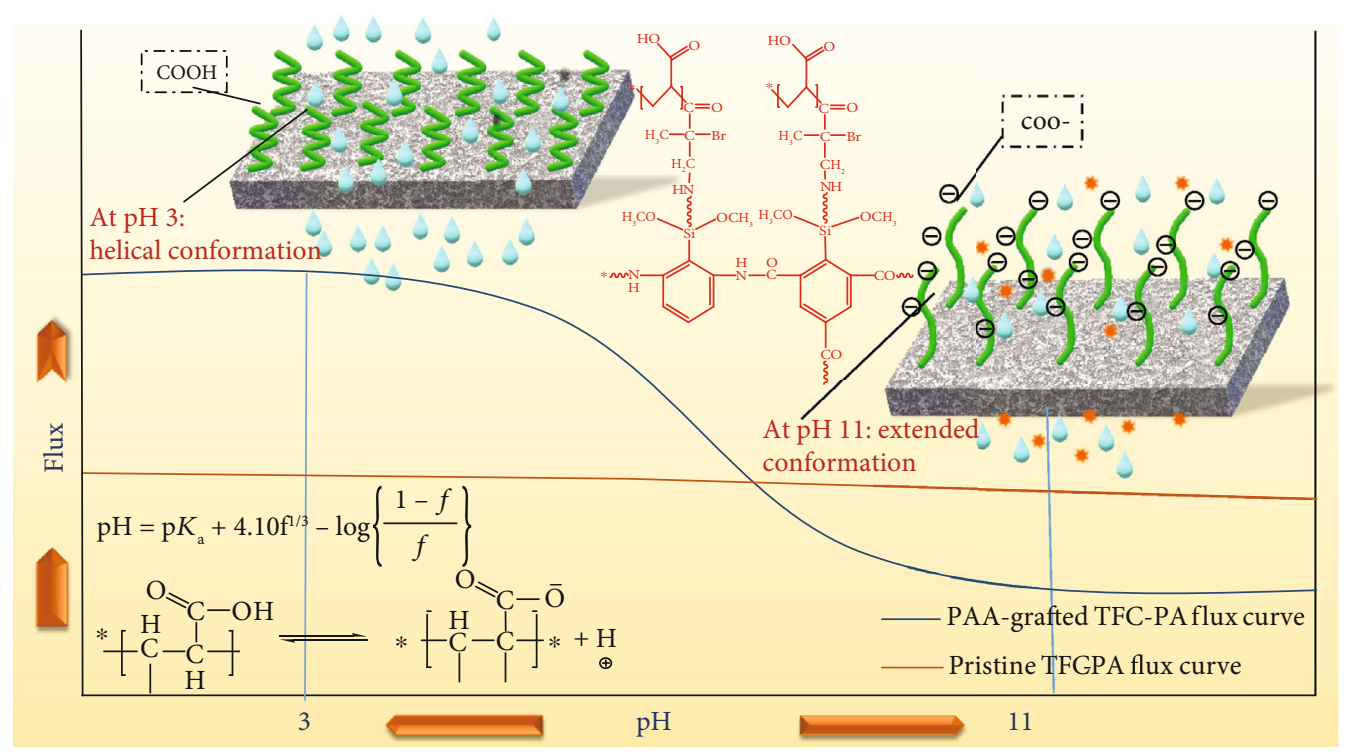

Scheme 3: Overview of $\mathrm{pH}$ switchable behavior of PAA-g-PA TFC-RO membrane.<smiles>C=CC(C)C(C(=O)O)C(C)C(C)(C)C</smiles>

Scheme 4: PAA reversible swelling-shrinking behavior.

these $\mathrm{pH}$ values, the transition in chain configuration as a function of $\mathrm{p} K_{a}$ can take place with the subsequent regulation of water permeability and salt rejection as observed in the present work. This transformation is sensitive to water $\mathrm{pH}$ and results in swelling and deswelling of PAA brushes [56], and the main factors that mainly govern the conformation of polyelectrolyte chains are electrostatic interactions, solvation forces, and excluded volume effects [57].

Scheme 3 presents an overview of the effect of $\mathrm{pH}$ on flux variation and on polymer brush transformation changes involving helical and extended conformation. This transformation is sensitive to water $\mathrm{pH}$ and results in swelling and deswelling of PAA brushes [58].

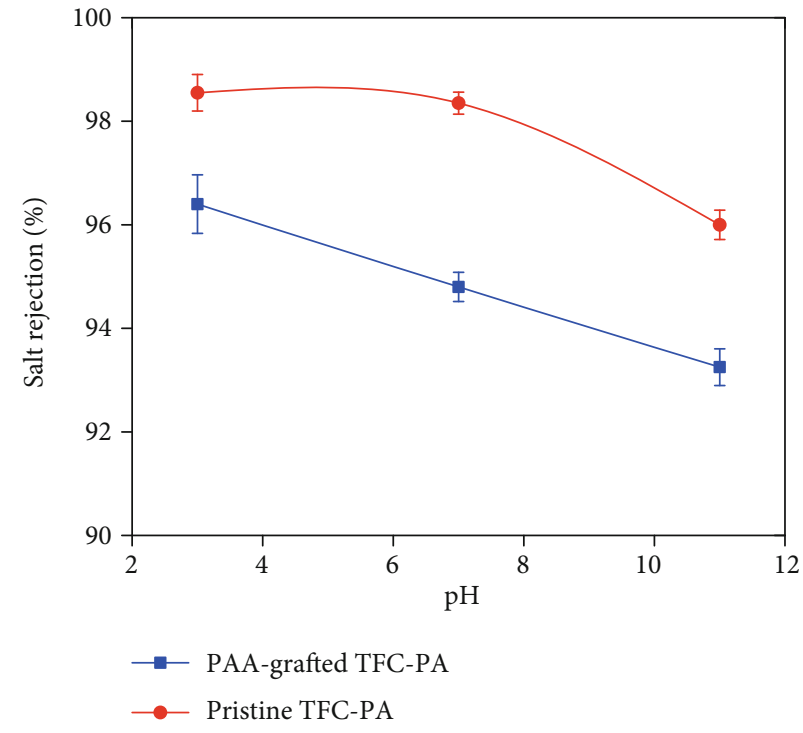

FIGURE 6: Salt rejection of TFC-PA pristine and grafted TFC-PA-g$\mathrm{PAA}$ at different $\mathrm{pH}$ values. 
TABle 1: Comparison of present work with the literature.

\begin{tabular}{lcccc}
\hline Monomer used on TFC-PA membrane & Feed pressure $(\mathrm{kPa})$ & Flux $\left(\mathrm{l} \mathrm{m}^{-2} \cdot \mathrm{hr}^{-1}\right)$ & Salt rejection (\%) & References \\
\hline PAA & 3309 & $82 \pm 2$ & $95 \pm 1.5 \%$ & Present work \\
PAA & 3447 & $78 \pm 2$ & $90 \pm 1.5 \%$ & 67 \\
NIPAM/ZnO & 6900 & 43 to 41 & $89 \%$ and $92 \%$ & 68 \\
PVA crosslinked with glutaraldehyde & 500 & 40 to 30 & 85 to $87 \%$ & 69 \\
PSBMA & 1500 to 4500 & 13 to 38 & 83 to 95.5 & 31 \\
\hline
\end{tabular}

In the present work, the dominant factor seems to be the electrostatic repulsion between the adjacent chains and the excluded volume effect of the solvated side chain groups which result in the stretched conformation of polyelectrolyte chains, whereas the coiled conformation is due to entropically favorable minimization of electrostatic repulsion [59]. PAA reversible swelling-shrinking behavior is caused by the transformation between the deionized form ( $\mathrm{COOH}$ group) and the ionized form $\left(\mathrm{COO}^{-}\right.$group) at $\mathrm{pH}$ values near a $\mathrm{p}$ $K_{a}$ of about 4.7 as shown in the equilibrium given below by Scheme 4 [60].

Furthermore, the permeability and separation performance of the $\mathrm{pH}$-sensitive membranes are highly dependent on the pore size change with the $\mathrm{pH}$ and the electroviscous effect [61]. Since TFC-PA-g-PAA is a surface-grafting $\mathrm{pH}$ sensitive membrane, both the pore size change and the electroviscous effect seems to affect the $\mathrm{pH}$-sensitivity, water flux, and salt rejection [61].

3.7. pH-Responsive Salt Rejection Evaluation. For the highpressure RO membrane, sodium chloride salt rejection is a good measure of its performance [62]. Salt rejection is measured at different $\mathrm{pH}$ values and is represented in Figure 6. $\mathrm{pH}$ changes appeared to not significantly affect the salt rejection for both pristine and modified membranes [31]. In the present work, $2000 \mathrm{ppm}$ solution of $\mathrm{NaCl}$ was used at $\mathrm{pH}$ values of $3,5,7$, and 11 . At $\mathrm{pH} 3$, the PAA-grafted PA membrane showed the maximum value of salt rejection at $95 \%$ [64]. This value is approximately similar to that of the commercial RO membranes which are in the range of 95 to 99.4\%. It should be kept in consideration that a modified grafted membrane exhibits a relatively higher flux of over $80 \mathrm{~L} \mathrm{~m}^{-2} \cdot \mathrm{hr}^{-1}$ as compared to pristine and commercially available membranes with a flux of $70 \mathrm{~L} \mathrm{~m}^{-2} \cdot \mathrm{hr}^{-1}$. This higher flux may result in lower salt rejection as membrane operation needs optimization between flux rate and salt rejection [64]. This observation is elaborated due to the $\mathrm{pH}$ effect on the charge-to-mass ratios of ions. At $\mathrm{pH} 3$, under acidic $\mathrm{pH}$, salt rejection is relatively higher and can be attributed to screening and the Donnan effect [65]. At a lower $\mathrm{pH}$ value, there is a competition between sodium and hydrogen ions, and hydrogen ions have a greater charge-to-mass ratio and are more mobile compared to sodium ions resulting in more rejection of salt [66]. At pH 11, under basic conditions, there is no such competition of the different charge-to-mass ratios of ions, so charge rejection comparatively decreases [29]. There are also various research work indicating that the incorporation of polymer brushes influenced flux and salt rejection as pre- sented in the Table 1 . In a related study, the TFC-PA membrane is grafted with PAA acid by RAFT polymerization that exhibited a water flux of $78 \pm 2 \mathrm{~L} \mathrm{~m}^{-2} \cdot \mathrm{hr}^{-1}$ and a salt rejection of $90 \pm 1.5 \%$ [67]. In another work, the TFC-PA membrane modified by NIPAM and $\mathrm{ZnO}$ using radiation grafting showed a water flux of $43 \mathrm{~L} \mathrm{~m}^{-2} \mathrm{hr}^{-1}$ and $41 \mathrm{~L} \mathrm{~m}^{-}$ ${ }^{2} \mathrm{hr}^{-1}$, while salt rejection shown by the modified membrane was found to be in the range of $89 \%$ and $92 \%$ [68]. In another relevant study, the TFC-PA membrane was grafted by polyvinyl alcohol (PVA) crosslinked with glutaraldehyde. The membrane showed a water flux of 40 to $30 \mathrm{~L} \mathrm{~m}^{-2} \mathrm{hr}^{-1}$, and salt rejection was found to be in the range of 85 to $87 \%$ [69]. The $\mathrm{pH}$-responsive salt rejection evaluation of the TFC-modified membranes with PAA brushes in the present work is valuable and support various studies discussed here and can lead to the next generation of advances in polymer membranes with simultaneous control of both flux and salt rejection.

\section{Conclusions}

pH-responsive polymer brushes of poly(acrylic acid) (PAA) were grafted through commercial TFC-PA reverse osmosis (RO). First, poly(t-butyl acrylate) chains were grafted on the surface of the membrane through surface-initiated atom transfer radical polymerization (SI-ATRP) followed by its hydrolysis to form a relatively more hydrophilic PAA brush surface. Membrane characterization results revealed that grafting of PAA brushes had noticeable effects on the membrane properties such as higher porosity, higher hydrophilicity with lower contact angle, and notable $\mathrm{pH}$ switchable permeation flux. For the pristine membranes, water flux remains stable with $\mathrm{pH}$ variation in the range of around $70 \mathrm{Lm}^{-2} \cdot \mathrm{hr}^{-1}$. In the case of modified membranes, a relatively higher water flux of around $81 \mathrm{Lm}^{-2} \cdot \mathrm{hr}^{-1}$ was observed with slight transition in flux with $\mathrm{pH}$ values changing in between 2 and 5. This transition is attributed to the conformational changes in the structure of polymer brush chains that originated below and above the $\mathrm{p} K_{a}$ of the $\mathrm{COOH}$ groups in the ionization of the polymer chain to regulate pore dimension in the modified membranes. At higher $\mathrm{pH}$, PAA brushes seem to be in extendable conformation to relatively block out the pores, while at lower $\mathrm{pH}$ values, these brushes exhibit tighter conformation that may lead to a wider pore with higher water flux rates. Evaluation of $\mathrm{NaCl}$ salt rejection as function of $\mathrm{pH}$ indicated that rejection percentage does not significantly differ with $\mathrm{pH}$ variation and remains close to pristine TFC-PA membranes. The modified membrane exhibited the switchable behavior at different $\mathrm{pH}$ values and 
provided interesting avenues to develop and explore the next generation of smart membrane technology for simultaneous water treatment with optimized flux rate and regulation of solute present in it.

\section{Data Availability}

All of the data used to support the findings of this study are included within the article.

\section{Conflicts of Interest}

There is no conflict of interest.

\section{Acknowledgments}

The authors are thankful to the NUST Research Directorate for financial support. Dr. Nasir M. Ahmad acknowledges the support of Higher Education Commission (HEC), NRPU through Project 6020.

\section{References}

[1] J. Ochando-Pulido, A. Martínez-Férez, and M. Stoller, "Analysis of the flux performance of different $\mathrm{RO} / \mathrm{NF}$ membranes in the treatment of agroindustrial wastewater by means of the boundary flux theory," Membranes, vol. 9, no. 1, p. 2.

[2] P. Akkahat, W. Mekboonsonglarp, S. Kiatkamjornwong, and V. P. Hoven, "Surface-grafted poly(acrylic acid) brushes as a precursor layer for biosensing applications: effect of graft density and swellability on the detection efficiency," Langmuir, vol. 28, no. 11, pp. 5302-5311, 2012.

[3] M. Adamczak, G. Kamińska, and J. Bohdziewicz, "Preparation of polymer membranes by in situ interfacial polymerization," International Journal of Polymer Science, vol. 2019, 13 pages.

[4] M. Mänttäri, A. Pihlajamäki, and M. Nyström, "Effect of pH on hydrophilicity and charge and their effect on the filtration efficiency of NF membranes at different pH," Journal of Membrane Science, vol. 280, no. 1-2, pp. 311-320, 2006.

[5] T. Wu, P. Gong, I. Szleifer, P. Vlček, V. Subr, and J. Genzer, "Behavior of surface-anchored poly(acrylic acid) brushes with grafting density gradients on solid substrates: 1 . Experiment," Macromolecules, vol. 40, no. 24, pp. 8756-8764, 2007.

[6] H. Y. Lee, Y. H. Park, and K. H. Ko, "Correlation between surface morphology and hydrophilic/hydrophobic conversion of MOCVD-TiO2Films," Langmuir, vol. 16, no. 18, pp. 72897293, 2000.

[7] L. Zhao, P. C. Y. Chang, and W. S. W. Ho, "High-flux reverse osmosis membranes incorporated with hydrophilic additives for brackish water desalination," Desalination, vol. 308, pp. 225-232, 2013.

[8] S.-C. Low and Q.-H. Ng, Progress of stimuli responsive membranes in water treatment, Elsevier Inc., 2019.

[9] M. A. U. R. Alvi, M. W. Khalid, N. M. Ahmad et al., "Polymer concentration and solvent variation correlation with the morphology and water filtration analysis of polyether sulfone microfiltration membrane," Advances in Polymer Technology, vol. 2019, 11 pages, 2019.

[10] Y. Mansourpanah, S. S. Madaeni, A. Rahimpour, Z. Kheirollahi, and M. Adeli, "Changing the performance and morphology of polyethersulfone/polyimide blend nanofil- tration membranes using trimethylamine," Desalination, vol. 256, no. 1-3, pp. 101-107, 2010.

[11] A. Al Mayyahi, "Important approaches to enhance reverse osmosis (RO) thin film composite (TFC) membranes performance," Membranes, vol. 8, no. 3, p. 68, 2018.

[12] S. Yu, Z. Lü, Z. Chen, X. Liu, M. Liu, and C. Gao, "Surface modification of thin-film composite polyamide reverse osmosis membranes by coating $\mathrm{N}$-isopropylacrylamide-co-acrylic acid copolymers for improved membrane properties," Journal of Membrane Science, vol. 371, no. 1-2, pp. 293-306, 2011.

[13] C. Zhao, X. Liu, S. Rikimaru, M. Nomizu, and N. Nishi, "Surface characterization of polysulfone membranes modified by DNA immobilization," Journal of Membrane Science, vol. 214, no. 2, pp. 179-189, 2003.

[14] A. A. M. F. Filho and A. S. Gomes, "Copolymerization of styrene onto polyethersulfone films induced by gamma ray irradiation," Polymer Bulletin, vol. 57, no. 4, pp. 415-421, 2006.

[15] A. Schulze, B. Marquardt, M. Went, A. Prager, and M. R. Buchmeiser, "Electron beam-based functionalization of polymer membranes," Water Science and Technology, vol. 65, no. 3, pp. 574-580, 2012.

[16] N. Saxena, C. Prabhavathy, S. De, and S. DasGupta, "Flux enhancement by argon-oxygen plasma treatment of polyethersulfone membranes," Separation and Purification Technology, vol. 70, no. 2, pp. 160-165, 2009.

[17] L. J. Mu and W. Z. Zhao, "Hydrophilic modification of polyethersulfone porous membranes via a thermal- induced surface crosslinking approach," Applied Surface Science, vol. 255, no. 16, pp. 7273-7278, 2009.

[18] C. J. Fristrup, K. Jankova, and S. Hvilsted, "Surface-initiated atom transfer radical polymerization-a technique to develop biofunctional coatings," Soft Matter, vol. 5, no. 23, pp. 46234634, 2009.

[19] K. Lee, K. Kim, H. Yoon, and H. Kim, "Chemical design of functional polymer structures for biosensors: from nanoscale to macroscale," Polymers, vol. 10, no. 5, p. 551, 2018.

[20] S. Peng and B. Bhushan, "RSC advances smart polymer brushes and their emerging applications," RSC Advances, pp. 85578578, 2012.

[21] J. F. Hester, S. C. Olugebefola, and A. M. Mayes, "Preparation of pH-responsive polymer membranes by self-organization," Journal of Membrane Science, vol. 208, no. 1-2, pp. 375-388, 2002.

[22] D. Rana and T. Matsuura, "Surface modifications for antifouling membranes," Chemical Reviews, vol. 110, no. 4, pp. 2448 2471, 2010.

[23] S. P. Adiga and D. W. Brenner, "stimuli-responsive polymer brushes for flow control through nanopores," Journal of Functional Biomaterials, vol. 3, no. 2, pp. 239-256, 2012.

[24] F.-J. Xu, E.-T. Kang, and K.-G. Neoh, "pH- and temperatureresponsive hydrogels from crosslinked triblock copolymers prepared via consecutive atom transfer radical polymerizations," Biomaterials, vol. 27, no. 14, pp. 2787-2797, 2006.

[25] C. Scott, B. Mitrovic, S. Eastwood, and G. Kinsel, "Stimuli response of cationic polymer brush prepared by ATRP: application in peptide fractionation," Polymer, vol. 55, no. 16, pp. 3551-3556.

[26] M. Ulbricht, "Advanced functional polymer membranes," Polymer, vol. 47, no. 7, pp. 2217-2262, 2006.

[27] N. Ahmad, P. Goh, Z. A. Karim, and A. Ismail, "Thin film composite membrane for oily waste water treatment: recent advances and challenges," Membranes, vol. 8, no. 4, p. 86. 
[28] L. Xiao, D. M. Davenport, L. Ormsbee, and D. Bhattacharyya, "Polymerization and functionalization of membrane pores for water related applications," Industrial \& Engineering Chemistry Research, vol. 54, no. 16, pp. 4174-4182.

[29] J. Luo and Y. Wan, "Effects of $\mathrm{pH}$ and salt on nanofiltration-a critical review," Journal of Membrane Science, vol. 438, pp. 1828,2013

[30] N. S. K. Gunda, M. Singh, L. Norman, K. Kaur, and S. K. Mitra, "Optimization and characterization of biomolecule immobilization on silicon substrates using (3-aminopropyl)triethoxysilane (APTES) and glutaraldehyde linker," Applied Surface Science, vol. 305, pp. 522-530, 2014.

[31] Y. Zhang, Z. Wang, W. Lin, H. Sun, L. Wu, and S. Chen, “A facile method for polyamide membrane modification by poly(sulfobetaine methacrylate) to improve fouling resistance," Journal of Membrane Science, vol. 446, pp. 164-170, 2013.

[32] C. Scholz and K. Matyjaszewski, "Advances in atom transfer radical polymerization," Polymer International, vol. 63, no. 5, pp. 801-802, 2014.

[33] Y. Chen, Z. Wang, Y. He et al., "Light-enabled reversible selfassembly and tunable optical properties of stable hairy nanoparticles," Proceedings of the National Academy of Sciences, vol. 115, no. 7, pp. E1391-E1400, 2018.

[34] S. Abraham, C.-S. Ha, and I. Kim, "Synthesis of poly(styreneblock-tert-butyl acrylate) star polymers by atom transfer radical polymerization and micellization of their hydrolyzed polymers," Journal of Polymer Science Part A: Polymer Chemistry, vol. 43, no. 24, pp. 6367-6378, 2005.

[35] C. Piñón-Balderrama, C. Leyva-Porras, R. Olayo-Valles et al., "Self-Assembly Investigations of Sulfonated Poly(methyl methacrylate-block- styrene) Diblock Copolymer Thin Films," Advances in Polymer Technology, vol. 2019, 11 pages, 2019.

[36] S. Matsumura, A. R. Hlil, C. Lepiller et al., "Ionomers for proton exchange membrane fuel cells with sulfonic acid groups on the end-groups: novel branched poly(ether-ketone)s," American Chemical Society, Polymer Preprints, Division of Polymer Chemistry, vol. 49, pp. 511-512, 2008.

[37] B. Li, Y. Shi, W. Zhu, Z. Fu, and W. Yang, "Synthesis of Amphiphilic Polystyrene- _b_ -Poly(acrylic acid) Diblock Copolymers by Iodide-Mediated Radical Polymerization," Polymer Journal, vol. 38, no. 4, pp. 387-394, 2006.

[38] V. Yadav, A. V. Harkin, M. L. Robertson, and J. C. Conrad, "Hysteretic memory in $\mathrm{pH}$-response of water contact angle on poly(acrylic acid) brushes," Soft Matter, vol. 12, no. 15, pp. 3589-3599, 2016.

[39] J. Wang and P. Somasundaran, "Reversible conformational behavior of poly(acrylic acid) LB film with changes in $\mathrm{pH}$, ionic strength and time," Colloids and Surfaces A: Physicochemical and Engineering Aspects, vol. 273, no. 1-3, pp. 6369, 2006.

[40] M. C. Lukowiak, S. Wettmarshausen, G. Hidde et al., "Polyglycerol coated polypropylene surfaces for protein and bacteria resistance," Polymer Chemistry, vol. 6, no. 8, pp. 1350-1359, 2015.

[41] J. Lejnieks, A. Mourran, W. Tillmann, H. Keul, and M. Möller, "Thin film of Poly(acrylic acid-co-allyl acrylate) as a Sacrificial Protective layer for hydrophilic self cleaning glass," Materials, vol. 3, no. 5, pp. 3369-3384, 2010.

[42] E. Virga, E. Spruijt, W. M. De Vos, and P. M. Biesheuvel, "Wettability of amphoteric surfaces: the effect of $\mathrm{pH}$ and ionic strength on surface ionization and wetting," Langmuir, vol. 34, no. 50, pp. 15174-15180, 2018.
[43] S. Javed, I. H. Aljundi, and M. Khaled, "High foulingresistance of polyamide desalination-membrane modified with PEI/PAH polyelectrolyte multilayers," Journal of Environmental Chemical Engineering, vol. 5, no. 5, pp. 4594-4604, 2017.

[44] B.-H. Jeong, E. M. V. Hoek, Y. Yan et al., "Interfacial polymerization of thin film nanocomposites: a new concept for reverse osmosis membranes," Journal of Membrane Science, vol. 294, no. 1-2, pp. 1-7, 2007.

[45] M. S. Rahaman, H. Thérien-Aubin, M. Ben-Sasson, C. K. Ober, M. Nielsen, and M. Elimelech, "Control of biofouling on reverse osmosis polyamide membranes modified with biocidal nanoparticles and antifouling polymer brushes," Journal of Materials Chemistry B, vol. 2, no. 12, pp. 17241732, 2014.

[46] M. Kobayashi, Y. Terayama, H. Yamaguchi et al., "Wettability and antifouling behavior on the surfaces of superhydrophilic polymer brushes," Langmuir, vol. 28, no. 18, pp. 7212-7222, 2012.

[47] C. H. Mathis, R. Simič, C. Kang, S. N. Ramakrishna, L. Isa, and N. D. Spencer, "Indenting polymer brushes of varying grafting density in a viscous fluid: a gradient approach to understanding fluid confinement," Polymer, vol. 169, pp. 115-123, 2019.

[48] B. S. Lalia, V. Kochkodan, R. Hashaikeh, and N. Hilal, "A review on membrane fabrication: structure, properties and performance relationship," Desalination, vol. 326, pp. 77-95, 2013.

[49] M. Motornov, S. Minko, M. Nitschke, K. Grundke, and M. Stamm, "Mixed polymer brushes on polyamide substrates," Polymeric Materials: Science \& Engineering, pp. 264-265, 2003.

[50] L. Lim, N. Rosli, I. Ahmad, A. M. Lazim, and M. M. Amin, "Synthesis and swelling behavior of $\mathrm{pH}$-sensitive semi-IPN superabsorbent hydrogels based on poly(acrylic acid) reinforced with cellulose nanocrystals," Nanomaterials, vol. 7, no. 11, p. 399.

[51] T. Swift, L. Swanson, M. Geoghegan, and S. Rimmer, “The pHresponsive behaviour of poly(acrylic acid) in aqueous solution is dependent on molar mass," Soft Matter, vol. 12, no. 9, pp. 2542-2549, 2016.

[52] A. M. Mika, R. F. Childs, J. M. Dickson, B. E. Mccarry, and D. R. Gagnon, "A new class of polyelectrolyte-filled microfiltration membranes with environmentally controlled porosity," Journal of Membrane Science, vol. 108, no. 1-2, pp. 37-56, 1995.

[53] C. Ren, R. J. Nap, and I. Szleifer, "The role of hydrogen bonding in tethered polymer layers," The Journal of Physical Chemistry B, vol. 112, no. 50, pp. 16238-16248, 2008.

[54] S. Sekar, Fine tuning of electrostatic interaction between nanomaterials in solutions and at interfaces: towards the fabrication of hybrid functional surfaces(Doctoral dissertation, Université Sciences et Technologies-Bordeaux I).

[55] Y. Tian, T. A. Hatton, and K. C. Tam, "Dissociation and thermal characteristics of poly(acrylic acid) modified pluronic block copolymers in aqueous solution," Polymer, vol. 55, no. 16, pp. 3886-3893, 2014.

[56] D. Davenport, M. Gui, L. Ormsbee, and D. Bhattacharyya, "Development of PVDF membrane nanocomposites via various functionalization approaches for environmental applications," Polymers, vol. 8, no. 2, p. 32.

[57] O. Azzaroni, A. . A. Brown, and W.. T. . S. Huck, "Tunable wettability by clicking counterions into polyelectrolyte 
brushes**," Advanced Materials, vol. 19, no. 1, pp. 151-154, 2007.

[58] B. Lego, W. G. Skene, and S. Giasson, "Swelling study of responsive polyelectrolyte brushes grafted from mica substrates: effect of $\mathrm{pH}$, salt, and grafting density," Macromolecules, vol. 43, no. 9, pp. 4384-4393, 2010.

[59] Y. Su and C. Li, "Tunable water flux of a weak polyelectrolyte ultrafiltration membrane," Journal of Membrane Science, vol. 305, no. 1-2, pp. 271-278, 2007.

[60] J. Hendri, A. Hiroki, Y. Maekawa, M. Yoshida, and R. Katakai, "Permeability control of metal ions using temperature- and pH-sensitive gel membranes," Radiation Physics and Chemistry, vol. 60, no. 6, pp. 617-624, 2001.

[61] C. Zhao, S. Nie, M. Tang, and S. Sun, "Polymeric pH-sensitive membranes-A review," Progress in Polymer Science, vol. 36, no. 11, pp. 1499-1520, 2011.

[62] L. Zou, I. Vidalis, D. Steele, A. Michelmore, S. P. Low, and J. Q. J. C. Verberk, "Surface hydrophilic modification of RO membranes by plasma polymerization for low organic fouling," Journal of Membrane Science, vol. 369, no. 1-2, pp. 420-428.

[63] S. Bandini, J. Drei, and D. Vezzani, "The role of $\mathrm{pH}$ and concentration on the ion rejection in polyamide nanofiltration membranes," Journal of Membrane Science, vol. 264, no. 1-2, pp. 65-74, 2005.

[64] B. Khorshidi, T. Thundat, B. A. Fleck, and M. Sadrzadeh, “A novel approach toward fabrication of high performance thin film composite polyamide membranes," Scientific Reports, vol. 6, no. 1, pp. 1-10, 2016.

[65] X. Wei, X. Bao, J. Wu et al., "Typical pharmaceutical molecule removal behavior from water by positively and negatively charged composite hollow fiber nanofiltration membranes," RSC Advances, vol. 8, no. 19, pp. 10396-10408, 2018.

[66] S. Szoke, G. Patzay, and L. Weiser, "Characteristics of thin-film nanofiltration membranes at various $\mathrm{pH}$-values," Desalination, vol. 151, no. 2, pp. 123-129, 2003.

[67] K. Gao, L. T. Kearney, R. Wang, and J. A. Howarter, "Enhanced wettability and transport control of ultrafiltration and reverse osmosis membranes with grafted polyelectrolytes," ACS Applied Materials \& Interfaces, vol. 7, no. 44, pp. 2483924847, 2015.

[68] M. B. El-Arnaouty, A. M. Abdel Ghaffar, M. Eid, M. E. Aboulfotouh, N. H. Taher, and E.-S. Soliman, "Nano-modification of polyamide thin film composite reverse osmosis membranes by radiation grafting," Journal of Radiation Research and Applied Science, vol. 11, no. 3, pp. 204-216, 2018.

[69] G. Kasongo, C. Steenberg, B. Morris, G. Kapenda, N. Jacobs, and M. Aziz, "Surface grafting of polyvinyl alcohol (PVA) cross-linked with glutaraldehyde (GA) to improve resistance to fouling of aromatic polyamide thin film composite reverse osmosis membranes using municipal membrane bioreactor effluent," Water Practice Technology, vol. 14, no. 3, pp. 614624, 2019. 